\title{
Getting in and getting out: Predicting the likelihood of graduation of master's program students
}

\section{Lukkarinen, Anna ${ }^{a}$ and Koivukangas, Paula ${ }^{b}$}

${ }^{a}$ Department of Information and Service Economy, Aalto University School of Business, Finland, ${ }^{\mathrm{b}}$ Learning Services, Aalto University School of Business, Finland.

\begin{abstract}
We assess the predictors of the likelihood that a student will graduate from the master's program of a business university. We use data from three years of a master's program, totaling 455 students. The methods used are bivariate tests and logistic regression analysis. We find that the likelihood of a student graduating from the master's program is positively related to the student i) holding their previous degree from business, as opposed to another field, ii) moving from another country to take the master's program, and iii) taking up a master's program with a qualitative, rather than quantitative, orientation. Interestingly, we find no evidence to suggest that whether a student's previous degree is from a research university or from a practically oriented polytechnic would be related to the student's odds of graduating. The results are relevant for master's program teachers who can benefit from taking into account their students' varying backgrounds, and for people responsible for planning the selection criteria and implementation of master's programs. The results are also encouraging for polytechnic students who are contemplating taking further studies at a research university.
\end{abstract}

Keywords: Admission criteria; completion of studies; graduation; master's program; master's studies; polytechnic. 


\section{Introduction}

As admission to universities is limited, universities use a variety of student selection criteria. The aim of these criteria is to ensure that students have the appropriate background, competencies, and motivation to successfully complete their university studies. It is typically in the interests of universities and students alike that students eventually graduate. The amount of public funding received by a university can also be tied to the number of graduations. It is therefore important to attract and select students who are likely to graduate.

Existing research assessing the ability of admission criteria to predict master students' academic success is not entirely consistent in its findings. Studies regarding the influence of standardized test scores and undergraduate grade point averages (GPA) have yielded varying results (Calisir et al., 2016; Clayton \& Cate, 2004; Graham, 1991; Marks et al., 1981; Zhang et al., 2004). For example, Zhang et al. (2004) found that standardized test scores and previous GPAs are significant predictors of graduation, whereas Clayton and Cate (2004) did not find them significant. Fastre et al. (2008) found that the quantitative skills of master business students are positively related to a background in business and to university-level bachelor's degrees. They also found that students entering a European university from outside Europe have higher quantitative skills than their colleagues. Zhang et al. (2004) showed that ethnicity and citizenship are significant predictors of the likelihood of graduation in some universities but not in others. Lamadrid-Figueroa et al. (2012) and Zhang et al. (2004) both highlighted that gender or age are not significant in predicting the odds of graduation.

In this paper, we investigate the predictors of the likelihood that a student will graduate from the master's program of a business university. We examine the influence of students' educational backgrounds, age, gender, and the orientation of their major subjects on the odds of graduation. ${ }^{1}$ We thereby seek to contribute to the existing body of research on factors affecting the likelihood of graduation.

\footnotetext{
1 Due to data availability restrictions, we do not assess the impact of standardized test scores or previous degrees' GPAs.
} 


\section{Method}

\subsection{Data collection}

We use data from the master's program of a Finnish business university. The sample includes students who entered the master's program in 2009, 2010, and 2011. ${ }^{2}$ These entry years were selected in order to allow for sufficient time to have passed for the students to have graduated. The data were sourced from the internal student information database of the university.

\subsection{Variables}

Graduation is the dependent variable of this study. It is an indicator variable with the value of 0 for students who have not graduated and 1 for students who have graduated by 2017 .

The four independent variables of this study are described below.

Type of previous degree. Higher education in Finland is offered by research universities and by polytechnics. Research universities emphasize scientific research, whereas polytechnics adopt a more practical approach. Bachelor's degrees from both research universities and polytechnics provide general eligibility for master's degree studies, and the sample contains students with both types of degrees. This variable is valued at 0 for polytechnics and 1 for research universities.

Study field. An indicator for whether or not the student's previous degree is in the same field as the master's program, i.e. business. Valued at 1 for business degrees and 0 for others.

Country. Indicates whether the student's previous degree is from the same country as the master's studies, i.e. Finland. Valued at 1 for degrees from Finland and 0 otherwise.

Orientation. An indicator variable showing whether the student's major in the master's program is quantitatively (1) or qualitatively (0) oriented. ${ }^{3}$

In addition, we use two control variables, which are described below.

Age. The age, in years, of the student when s/he entered the master's program.

Gender. An indicator variable with the value of 0 for male students and 1 for female students.

\footnotetext{
2 Students who continue directly from a bachelor's degree to master's studies at the same university are not included, as they do not need to apply for the master's program.

${ }^{3}$ Majors in business, management, leadership, communication, law, entrepreneurship, marketing, and strategy were classified as qualitative. Economics, management science, accounting, finance, and information technology were classified as quantitative.
} 


\section{Results}

\subsection{Description of the sample}

The sample consists of 455 students with previous degrees from 96 different universities and polytechnics from around the world. Their previous degrees are typically from the fields of business or engineering, although several other study fields, such as law and political science, are also represented. The majority (55\%) of the students are women. $70 \%$ of the sampled students graduated from the master's program, with women graduating somewhat more often $(75 \%)$ than men $(64 \%)$. The median age at the time of entering the master's program was 24 years for students who proceeded to graduate and 26 years for students who did not graduate.

\subsection{Bivariate analysis}

Table 1 presents the number and share of students split according to whether or not they graduated, separately for each categorical variable value. It is noteworthy that $76 \%$ of students with business degrees graduated, in contrast to $54 \%$ of students from other fields. Likewise, $59 \%$ of students in quantitatively oriented programs graduated, which compares to $75 \%$ in qualitatively oriented programs.

Table 1. Number of students in each category and $\chi 2$ test statistics.

\begin{tabular}{|c|c|c|c|c|c|c|c|c|}
\hline & \multicolumn{6}{|c|}{ Characteristics of previous degree } & \multirow{2}{*}{\multicolumn{2}{|c|}{$\begin{array}{c}\text { Master's program } \\
\text { Orientation }\end{array}$}} \\
\hline & \multicolumn{2}{|c|}{ Type } & \multicolumn{2}{|c|}{ Study field } & \multicolumn{2}{|c|}{ Country } & & \\
\hline & $\begin{array}{c}\text { Uni- } \\
\text { versity }\end{array}$ & $\begin{array}{l}\text { Poly- } \\
\text { technic }\end{array}$ & Business & $\begin{array}{l}\text { Other } \\
\text { field }\end{array}$ & Finland & $\begin{array}{l}\text { Other } \\
\text { country }\end{array}$ & $\begin{array}{l}\text { Quanti- } \\
\text { tative }\end{array}$ & $\begin{array}{l}\text { Quali- } \\
\text { tative }\end{array}$ \\
\hline Graduated & 237 & 82 & 255 & 64 & 266 & 53 & 79 & 240 \\
\hline$\%$ & $68 \%$ & $75 \%$ & $76 \%$ & $54 \%$ & $69 \%$ & $75 \%$ & $59 \%$ & $75 \%$ \\
\hline Did not graduate & 109 & 27 & 82 & 54 & 118 & 18 & 54 & 82 \\
\hline$\%$ & $32 \%$ & $25 \%$ & $24 \%$ & $46 \%$ & $31 \%$ & $25 \%$ & $41 \%$ & $25 \%$ \\
\hline Total & 346 & 109 & 337 & 118 & 384 & 71 & 133 & 322 \\
\hline$\chi^{2}$ test statistic & \multicolumn{2}{|c|}{1.8} & \multicolumn{2}{|c|}{19.2} & \multicolumn{2}{|c|}{0.8} & \multicolumn{2}{|c|}{10.3} \\
\hline
\end{tabular}

Chi-squared tests were performed to assess whether each of the four independent variables has a statistically significant association with the number of graduations. The critical value of the chi-squared distribution at a significance level of $\alpha=0.05$ is $\chi^{2}(1)=3.84$. The data thus show sufficient evidence to indicate that whether or not a master's program student will graduate depends on the field of their previous degree, with business students more likely to graduate, and on the orientation of the master's program, with students in 
qualitatively oriented programs more likely to graduate. The bivariate tests do not indicate that graduation would depend on the type or country of the previous degree.

\subsection{Logistic regression to assess the likelihood of graduation}

Logistic regression was used to model the relationship between independent and control variables and the likelihood of graduation. In order to yield a parsimonious solution, regression was run hierarchically, gradually including the independent and control variables as well as their interactions ${ }^{4}$. The resulting model is presented in Table 2.

Table 2. Results of logistic regression to predict likelihood of graduation.

\begin{tabular}{llcccc}
\hline & & \multicolumn{4}{c}{ 95\% confidence interval for odds ratio } \\
Variable & Coefficient (b) & St. error & Lower & Odds ratio & Upper \\
\hline Constant & $2.78^{* * *}$ & 0.83 & & & \\
Type & -0.18 & 0.30 & 0.47 & 0.83 & 1.48 \\
Study field & $0.82 * * *$ & 0.26 & 1.35 & 2.26 & 3.80 \\
Country & $-0.54 *$ & 0.32 & 0.31 & 0.58 & 1.09 \\
Orientation & $-0.56^{* *}$ & 0.24 & 0.36 & 0.57 & 0.91 \\
Age & $-0.07 * * *$ & 0.02 & 0.89 & 0.93 & 0.97 \\
Gender & 0.29 & 0.23 & 0.86 & 1.34 & 2.10 \\
\hline $\begin{array}{l}\text { Note. } * * * \mathrm{p}<0.01, * * \mathrm{p}<0.05, * \mathrm{p}<0.1 . R_{L}^{2}=0.08\left(\text { Hosmer } \& \text { Lemeshow), } R_{C S}^{2}=0.09\left(\text { Cox } \& \text { Snell), } R_{N}^{2}=0.13\right.\right. \\
\text { (Nagelkerke). } \chi^{2}(6)=42.18, \mathrm{p}<0.001 .\end{array}$ & & & &
\end{tabular}

The model represents a statistically significant fit for the data, as indicated by the chisquared statistic which is significant at 0.001 level. The model does not suffer from multicollinearity, as indicated by tolerance values and variance inflation factors ${ }^{5}$. It also

\footnotetext{
4 Interactions were excluded from the final model, as they did not contribute to the explanatory power of the models in a statistically significant manner.

5 Collinearity diagnostics were obtained by running a linear regression model with the same independent and dependent variables. The resulting model's tolerance values for each variable range from 0.781 to 0.943 , while Menard (2011) suggests that tolerance values below 0.2 can raise concerns about multicollinearity. The variance inflation factors range from 1.060 to 1.281 , while Myers (1990) suggests that any value greater than 10 indicates a problem with multicollinearity.
} 
satisfies the assumption of linearity ${ }^{6}$. The study field of the previous degree, the orientation of the master's program, and the age of the student are related to the likelihood of graduating in a statistically significant manner. The country of the previous degree is also statistically significant, albeit weakly. The type of the previous degree and gender are not related to the likelihood of graduation.

\subsection{Insights from students}

To build an understanding of the reasons underlying the identified relationships, we asked 45 master's program students via e-mail for their views of what influences their likelihood of graduating, receiving nine responses. Students from other countries or from polytechnics had sometimes initially faced challenges in adapting to the high level of independence and to the processes specific to a Finnish research university. However, after overcoming these challenges, high motivation emerged as a key strength. Students from both categories were motivated by a high freedom of choice and of opinion. The motivation of students from other countries was positively influenced by the opportunity to end up with two degrees from two different countries. Students from polytechnics were motivated by the new type of study environment and methods. Some were also driven forward by a willingness to demonstrate that they were equally capable of succeeding as their colleagues with backgrounds in research universities. Previous business studies were also seen as a strength for the ability to complete the program.

\footnotetext{
${ }^{6}$ The linearity of the relationship between the continuous control variable (age) and the log of the outcome variable was tested by including the interaction between age and the natural logarithm of age in the logistic regression. The interaction term is not significant at 0.05 level, which indicates that the assumption of linearity has been met.
} 


\section{Conclusions}

\subsection{Discussion}

The bivariate tests and logistic regression gave results that are consistent with each other. They were further supported by the views obtained from students. The results are summarized in Figure 1 and discussed in what follows.

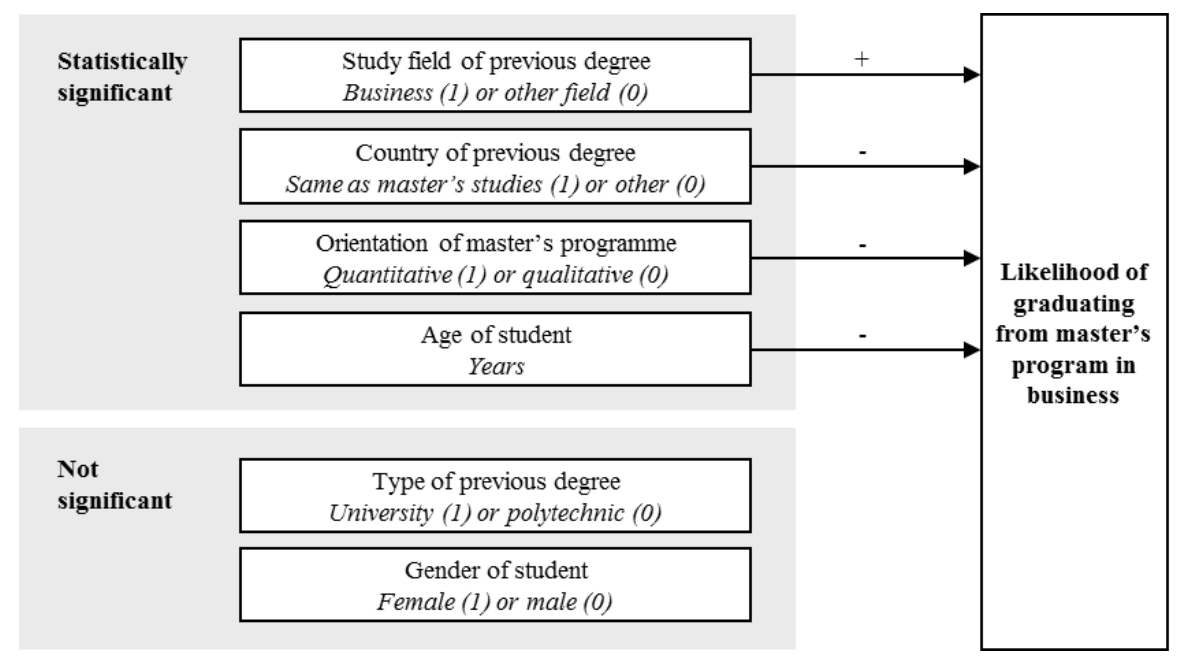

Figure 1. Illustration of the results.

A student having studied business in their previous degree is positively related to the likelihood of graduation. Students from fields other than business may be less likely to complete their master's studies because they may lack the necessary foreknowledge to successfully complete the business studies. Alternatively, they may be less motivated to complete their studies, as they already hold a degree from another field and may perceive the master's studies more as a way to selectively complement their education, rather than to earn a new degree. Furthermore, their preconception of business studies may have differed from reality, which may deter their motivation.

Students with previous degrees from abroad are more likely to graduate than those who completed their previous degree in the same country as the master's program. Students who come from abroad may have higher motivation to complete their master's studies if they have moved country because of the studies. Cultural differences in the attitude towards education may also play a role, with students from some other countries having more of the mindset that enrolling in a university implies the intent to also graduate.

A student attending a qualitatively, rather than quantitatively, oriented major in their master's program is positively related to the likelihood of graduation. Quantitative study 
fields have typically knowledge requirements of a more cumulative nature than qualitative fields. Hence the ability to complete a quantitative degree may be more reliant on the skillset that a student has acquired earlier on in their studies, which may complicate proceeding to graduation if that skillset is not fully in place.

Interestingly, there is no relationship between graduation and whether a student holds their previous degree from a research university or from a polytechnic. While students from polytechnics may need to acquire more new skills in order to complete their master's studies, they may also have a higher motivation to gain a university degree than their colleagues who already hold one degree from a university.

\subsection{Relevance}

The results are relevant for teachers of master's courses and for the admission boards of master's programs. They may benefit from taking into account that certain characteristics of students' previous degrees can be related to the students' ability or motivation to complete their master's studies. In particular, students with a degree from a different field may need extra motivation or support. It is also useful to take into account that students with a polytechnic background can be equally, if not even more, likely to complete their university-level master's studies as students with a university background. The results are also encouraging for polytechnic students who are contemplating taking further studies at a research university.

\subsection{Limitations and future research}

While our sample consists of a large data set, student groups with certain types of backgrounds, such as students coming from certain schools, are more heavily represented than others. Future research could include master's programs from additional universities. It would also be interesting to complement our results with a more extensive assessment of the reasons underlying the observed relationships. The results have been obtained from a country in which higher education was free of charge to all students. They may thus not be generalizable to institutions with study fees, as cost may affect motivation. 


\section{References}

Calisir, F., Basak, E., \& Comertoglu, S. (2016). Predicting academic performance of master's students in engineering management. College Student Journal, 50, 501-512.

Clayton, G. E., \& Cate, T. (2004). Predicting MBA no-shows and graduation success with discriminate analysis. International Advances in Economic Research, 10, 235-243.

Fastre, G., Gijselaers, W., \& Segers, M. (2008). Selection to ensure study success: Looking for multiple criteria in the case of a European Master of Science program in business. Journal of Education for Business, 84, 47-54.

Graham, L. D. (1991). Predicting academic success of students in a master of business administration program. Educational and Psychological Measurement, 51, 721-727.

Lamadrid-Figueroa, H., Castillo-Castillo, L., Fritz-Hernández, J., \& Magaña-Valladares, L. (2012). Admissions criteria as predictors of students' academic success in master's degree programs at the National Institute of Public Health of Mexico. Public Health Reports, 127, 605-611.

Marks, R., Watt, P., \& Yetton, P. (1981). GMAT scores and performance: Selecting students into a graduate management school. Australian Journal of Management, 6(2), 81-103.

Menard, S. (2011). Applied logistic regression analysis. Thousand Oaks, CA: Sage.

Myers, R. H. (1990). Classical and modern regression with applications. Boston, MA: PWS-KENT.

Zhang, G., Anderson, T. J., Ohland, M. W., \& Thorndyke, B. R. (2004). Identifying factors influencing engineering student graduation: A longitudinal and cross-institutional study. Journal of Engineering Education, 93, 313-320. 